\title{
EPS Council Meets in Dresden
}

\author{
The Council of EPS meets each year around the beginning of Spring to hear \\ reports on the past year and discuss policies for the coming 12 months. The \\ venue changes from year to year, the last time in the DDR being in 1976 when the \\ meeting was held in Leipzig.
}

The welcome reserved for the delegates to the meetings of Council and various committees of the European Physical Society was not only warm and effective, but also showed itself in concrete terms as a large batch of Individual Ordinary Members from the DDR were admitted to the Society (see April issue, page 56). Professor Buckel, officiating for the last time as President of EPS, and Professor Auth, the new President of the Physical Society of the DDR exchanged courtesies that were much more than mere formalities and the appreciation for the smoothness of the arrangements expressed to Dr. Hommel, the Secretary of the DDR Society was wholly sincere. The Council meeting was notable also for the number of delegates and proxies which made for a record total of 70 votes to be cast.

\section{Voting}

Not that formal voting is normally a major activity of the Council, apart from electing the new Executive Committee and this is rarely a subject of controversy. Professor Buckel was not offering himself for re-election as President and Council was happy to accept the recommendations of the out-going Executive Committee; no other candidates were forthcoming (although established procedure encourages proposals up to the very last moment). Professor Ricci of Padova was acclaimed the new President and while Professor Jacob of CERN is the new Secretary, Dr. Merz will remain on the Executive Committee as a non-voting member to assist him. For the full list, see April issue page 56 .

One vote, however, of critical importance to the financial stability of the Society was that of the unit fee to be applied from 1 January 1989. Council approved the Executive's proposal by more than the necessary three quarters majority of those voting that this should be raised to 12 SFR. This means that for 1989 the annual fee of a 4a) Individual Member will be 144 SFR, of a 4c) Individual Member (also member of an EPS group member) 48 SFR, of a Collaborating Society Member 60 SFR, while group members will be paying up to 59000 SFR according to their number of declared members.

\section{Advisory Committees}

In his report to the Council, the President reviewed the work of the Advisory Committees with obvious signs of satisfaction over the progress that had been made during his time in office.

The AC on Applied Physics and Physics in Industry's main achievement had been to establish the series of Europhysics Industrial Workshops, the first of which had been on pyroelectric arrays and the second on magneto-optic recording. The next will be in Rome from 22 24 June on SQUIDS followed by one in the Spring of 1989 on ion beams in materials research and technology. The formula for these meetings with a limit of about 50 participants - half from academe and half from industry, seemed to be about right. It was not far from that of a traditional Europhysics Study Conference, but the conclusion had been drawn that the explicit aims of these workshops warranted a distinct designation. Experience had also shown that the location should move around Europe, because even though no preference is given to local participants, a certain gravitational effect was inevitable.

Over the past two years the Publications Committee had completely reorientated its activities. The old Europhysics Journal designation had been replaced by a system of EPS Recognition for those European journals which had a broad international, notably European, content in the Editorial Board and in the list of active referees. So far 40 applications had been received and 35 had been accepted. One journal — Plasma Physics and Controlled Fusion on the request of the Plasma Physics Division had received Special Recognition, acknowledging a close and continuing relation between the journal and the Division. The old Europhysics Style Manual was being revised into a single European Guide to Authors so that one standard only need be followed when preparing a paper, irrespective of which journal would receive it. In part as an extension to this, and in part as a separate entity, the Committee was also developing a project to coordinate the development of the electronic preparation and transmission of papers, to simplify submission, communication with referees and the final conversion into print. As a first step, EPS would be inviting the Recognised Journals to take part in an enquiry amongst authors on the use of word processors for the preparation of scientific papers. A particular care of the EPS in furthering the project would be to look after the interests of physicists who did not have access to the latest techniques so that they were not put at a further disadvantage when submitting their work for publication. Concern had already been expressed at certain restrictions imposed on the use of scientific networks and whilst recognising the inevitability of some barriers to complete freedom of communication, the EPS would always have the complete equality of opportunity for its Members as an objective.

The Conference Committee, although well established and with a clear-cut mandate, had not allowed itself to become an automaton. It had recently been revising the rules to cover approval and sponsorship as well as recommendations to conference organisers and the Secretariat had brought up to date and simplified the material it sent out to applicants. The Committee had also examined its future role and concluded that it was still a necessary body even though the day to day work was now routine. It was much regretted that the present Chairman, Dr. J. Heijn was being obliged by his employer to give up the post and we were fortunate that Professor K. Bethge of Frankfurt/M was willing at short notice to step into his shoes.

The Physics Education Committee had been of late mainly preoccupied with secondary education and the use of computers in teaching. It had also sought and obtained approval from the Executive Committee for taking under 
its wing an ad hoc group that was concerned with promoting studies of the history of physics and giving a historical basis to physics teaching. This group has applied to the Communities (ERASMUS project) for a grant to pay for the preparation of specific texts that teachers can use in their courses.

The Physics and Society Committee was in a state of transition not only because Dr. David Parkinson after six years of firm leadership was handing over the reins to Sir Alec Merrison. The report on employment would take care of this sector for some time, while the report on nuclear winters was still being digested by the different authorities; research groups in different countries were collaborating on studies (notably of dust) to firm up some of the pertinent data, and on climatic modelling. A wide range of topics had been put forward for further activity, some directly aimed at promoting $\mathrm{E}-\mathrm{W}$ collaboration in difficult areas, some more generally concerned with the problems of controlling large systems which may be susceptible to the onset of chaos, some more explicitly directed towards environmental/supply problems of our time in which the science content is high. No choice has yet been made, but in the meantime a European-wide enquiry is being made into student and teacher attitudes towards physics to see what we can learn from this.

Nothing was to be heard from the Scientific Freedom Committee - a welcome sign that relations between European countries really are improving and that the easing of tension we all sense is more than just a surface relaxation.

\section{Communication Within the Society}

When discussions opened and the Divisions made their reports it was clear that a new spirit is moving through the European Physical Society that can be described as a will for greater identification with the Society. There are still many who are content to let the Society just happen and there are still odd pockets of resistance where perhaps individuals rather than whole sectors wish to carry on independently outside the general community. Nevertheless, the tide is flowing towards a greater participation in the life of the Society and to giving the Society a greater visibility in the life of European physics.

One sign of this is the production of newsletters following those already appearing in Plasma Physics and Controlled Fusion (Plasma Physics) and in Applied Physics $B$ (Quantum Electronics). The latest include: one started by the
Solar Physics Section of the Astronomy and Astrophysics Division, another planned by the Atomic and Molecular Physics Division in molecular physics, another by the Computational Physics Group (electronic, of course) and yet another by the Physics for Development Group. This stimulated a general discussion on how best members of a Division could communicate with each other and to what extent Europhysics News should be the vehicle. Arguments against are that, in the main, news needs to be diffused to a wider public than just EPS Members and that such news is of interest only to the people directly concerned and makes dull reading for others. On the other hand, Individual Ordinary Members could expect to have preferred treatment over nonmembers and one of the functions of Europhysics News was to give a general overview of what was going on in physics.

\section{Europhysics News}

This is not a new debate, but has recurred periodically throughout the life of the Society, although the emphasis has varied. Many members would, in any case, like to see a fatter Europhysics News giving the broad range of information that is to be found in Physics Today - backed of course by a corresponding income. Others see the difficulties in the mixed community that Europe constitutes with different traditions regarding information flow and willingness to defend publicly a particular platform, and also recognize that the marketing strategies adopted by manufacturers are totally different in the USA from those applicable in Europe. Moreover there are many people, inundated with paper, who find the very thinness of Europhysics News one of its merits. The debate will clearly go on and changes are not excluded in this period leading up to 1992 , when nearly half the countries with group members in EPS are due to dismantle their tariff barriers, so affecting markets generally.

But in the meantime, to clear up any misunderstandings as to the present policy of Europhysics News, let us summarise it now:

We publish as many pages as the Executive Committee decides the EPS can afford, and we pack these with review articles on physics, in collaboration with the Divisions, and information on the Society that we believe will be of general interest. We give priority to Divisional news and indeed any Society news that has a topical aspect, and we welcome readers letters on all topics that are scientific or related to the activities of the Society. We reserve the right, of course, to refuse unsuitable letters, but the number that have suffered this fate in the past is almost zero. We welcome (non-political) advertisements and we periodically try to bring in more industrial advertising (usually with minimal results).

\section{IOM Delegates Meet}

Dr. Stacey of Oxford, whose call to IOMs to communicate with their delegates to Council we published in the February issue (page 30), was disappointed with the zero response and in Dresden stimulated a meeting among the IOM delegates to discuss how they could be more effective in the future and how they saw the Society developing. This was seen as a welcome new initiative that could have important repercussions in the future and, in turn, could lead to a growth in the number of IOMs.

\section{Recruiting}

Recruiting is a permanent problem, as the wastage in terms of non-payers about balances the influx of new members and it is only through dedicated action that improvements can be made. The potential is there, but tapping it is very difficult and demands an effort from all existing Members. The Finance Committee has its representatives in many countries, but they can only be a spearhead, particularly as it is in the biggest countries that the greatest opportunities lie.

\section{Money}

On the financial side, we finished 1987 with the substantial deficit of nearly 97000 SFR, in part arising from the salaries of the extra staff needed to cope with the great surge in Europhysics Letters (q.v.). Forecasts for 1988, with the transferring of all the staff costs of Europhysics Letters to the journal, are that we shall have a surplus of something over 10000 SFR counting the nonrecurring income from the sales of the Proceedings of the Uppsala Conference organized by the High Energy and Particle Physics Division in June of last year. The additional contribution from HEPP to the Young Physicists' Fund of 5000 SFR does not figure in the general accounts. In 1989, the increase in the unit fee will have its effect and we should have a surplus for the year then approaching 20000 SFR which will go to paying off some of the outstanding deficit. All this, however, implies an operational plateau with no new initiatives. 


\section{Divisions and Groups}

The main activity of the Divisions is related to the organisation of their periodic conferences, the latest in the list being the European Quantum Electronics Conference to be held in alternate years starting with a meeting in Hannover in September this year. These "approved" conferences have now assumed a leading position in the European calendar of physics events. A major aspect of the meetings is to concentrate the specialists' attention and to limit duplication. It was therefore disturbing to find IUPAP sponsoring competitive conferences and refusing collaboration notably in the high energy and particle physics field, but also in atomic and molecular physics. Now it seems that better contact has been established and one can hope for the sort of cooperation that has now become established with the Nuclear Physics Division whose major problem is too many conferences.

Apart from the big general conferences and the specialised Section conferences, more attention is being given to establishing summer schools, such as the Materials Science and Technology Courses in Erice, the Chemical Physics Schools, the last of which took place in Santander in September 1987, as well as running Advanced Study Institutes, like that on Atomic and Molecular Collision Theory in Cortona, also in September' 87 .

This theme merges with the general desire to promote physics in the peripheral countries, also a central objective of the Group on Physics for Development. It is likely that a new school will be established in the near future aimed particulary at countries bordering the Mediterranean. The themes, which should be relevant to their economies, have yet to be settled. Over the period under review, however, it was central Africa that received the most attention from the IGPD and a workshop on materials and science in solar energy is planned for November in Tanzania.

Other activities of the Divisions additional to the newsletters already mentioned, and the compilation of Who's Whos - the Quantum Electronics Division since some time and the Condensed Matter Division just coming out - a number of Divisions are also discussing the creation of a prize to emulate the Hewlett-Packard Europhysics Prize in condensed matter.

The Computational Physics Group has in mind a number of ambitious projects: creation of electronic libraries, electronic mail system management; establishment of a video-cassette series on computer physics.

Council agreed without debate to annul the qualification of "provisional" applied to the Experimental Physics Control Systems Group when it was formed two years ago. This Group has got off to a flying start and now counts 18 laboratories as participants, each with its Contact Person. Latest in the list include the Czechoslovak Technical University, GSI Darmstadt and the Rutherford Appleton Lab. at Chilton in the UK. From Japan is JAERI (in particular the NAKA Fusion Research Centre) and KEK the Japanese National Laboratory for High Energy Physics. EPCS's Working Group on power convertor control protocols has already produced the draft of a standard in this field. The Group's first conference was reviewed in the February issue of Europhysics News (p. 22) when it was emphasised that through its activities smaller laboratories could expect to benefit from the experience of bigger laboratories, whilst these would benefit directly from cooperation.

In the Optics Division, elections to a regular Board are now in progress and all seems set for the first joint EPS/Europtica/SPIE conference to take place in Hamburg in September.

No decision has yet been taken on a European Astronomical Society (see Europhys. News, Nov./Dec., 1987, p. 137) but the subject is still under study. Also the question of a regular accelerator conference or a new inter-divisional group to cover accelerator design and development was still fluid.

\section{Other Societies}

Council agreed to grant the status of Collaborating Society to the Japan Society of Applied Physics which had offered reciprocal privileges. Council also took note of the formation of the Balkan Physical Union which brings together the physical societies of Albania, Bulgaria, Greece, Romania, Turkey and Yugoslavia. Its object is to:

Help promote physics in the areas,

strengthen the tradition in the physics communities,

establish a framework for close contacts in research and education.

The relation of the individual societies with EPS will not be affected.

\section{European Journal of Physics}

Recalling the appeals for manuscripts of a few years ago it was agreeable to hear that the European Journal of Physics could from the point of view of contributions contemplate going to six issues per year instead of four. New sec- tions had been introduced and cooperation with the Divisions was being intensified. A Study Group independent of the Board had been set up with the help of the Physics Education Committee to criticise the operations so far.

\section{Europhysics Letters}

Since the last Council Meeting the flow of good letters to Europhysics Letters had not ceased to grow, but it is now at a more manageable rate. Major changes have been made to the business structure as previous Associate Partners have been brought in as full Partners and the equivalent stake of EPS has been raised consequent upon its investment in terms of personnel during the growth period. Europhysics Letters now has societies from 16 countries as backers: (A, CH, D, F, H, I, NL, P, TR, Scandinavian pool, YU, UK). The input of the original partners - the French Physical Society, the Italian Physical Society and the UK Institute of Physics remains the same and equal, while new working capital, in total equal to the book value of one of the above has been contributed by the other partners; the EPS share has been adjusted to remain at $10 \%$. In addition, the German Physical Society has agreed to set aside a further sum of 45000 SFR as a reserve in case of need.

To avoid overweighting the Board, the new Partners will have one representative so that the Board counts five people in all. Major decisions require a $60 \%$ majority. Currently the books were nearly balanced, although the drop in the dollar had had some repercussions, but with the new capital behind it, the journal can look forward to a prosperous future. Great appreciation was expressed for the devoted and efficient work of the Editor and his Co-editors and the staff, in which the whole of Council joined.

\section{Lectures}

A number of delegates were giving lectures whilst visiting the DDR, and Council on its first evening was treated to talks by Professor $\mathrm{H}$. Gündel on 'Modern Aspects of New Light Sources' and Professor W. Pompe on 'Laser Pulse Vapour Deposits'. These were followed by a reception offered by the Physical Society of the DDR.

\section{Closure}

Council closed with a warm message of thanks from the new President to Professor Buckel and the best wishes of delegates and the staff on his retirement. The next meeting will be in Zagreb 16-17 March 1989. 